\title{
Między neoliberalizmem a feudalizmem. Godność młodych naukowców w kontekście transformacji polskiego uniwersytetu
}

\begin{abstract}
STRESZCZENIE. Artykuł przedstawia wyniki badań wstępnych prowadzonych z perspektywy zarządzania humanistycznego, dotyczących godności w miejscu pracy wśród osób rozpoczynających karierę akademicką na polskiej uczelni. Polscy doktoranci i osoby ze stopniem doktora znajdują się w momencie przejściowym między feudalizmem a neoliberalizmem oraz między „,samodzielnością” a „niesamodzielnością” naukową, co sprzyja upolitycznieniu ich tożsamości. Ma to niebagatelne skutki w kontekście procesów ochrony i ograniczania ich godności w miejscu pracy. Opisane zostaną neoliberalne zmiany w polskim szkolnictwie wyższym, poddana analizie kategoria godności z perspektywy zarządzania humanistycznego, a także zaprezentowane wyniki przeprowadzonego pilotażu badań jakościowych.
\end{abstract}

SŁOWA KLUCZOWE: kultura akademicka, godność, uniwersytet, neoliberalizm, zarządzanie performatywne

W państwie celów wszystko ma albo jakąś cenę, albo godność.

Kant 1953: 70.

\section{Wstęp}

Przemiany współczesnych uczelni, a szczególnie kultur akademickich poddanych presji neoliberalnych zmian (Sułkowski 2016; Ergöl i Coşar 2017), skłaniają do podjęcia pogłębionych badań nad godnością pracowników nauki. Pracoholizm, utrata równowagi między życiem prywatnym a zawodowym, depresja czy postawy nieetyczne to zjawiska, które coraz częściej można zaobserwować na uczelniach 
na świecie (Butler i Spoelstra 2012; Alvesson 2013; Knights i Clarke 2014; Ylijoki i Henriksson 2017). Wskazują one na możliwość występowania dysfunkcji w procesach zarządzania uczelniami, jak i patologii w samych kulturach organizacyjnych, które często kreują przestrzeń braku możliwości ochrony godności w miejscu pracy.

Szczególnie interesującym przypadkiem w kontekście zmian w szkolnictwie wyższym jest polski uniwersytet, będący organizacją reformowaną obecnie poprzez implementację neoliberalnego modelu reformy New Public Management, zakładającego wykorzystanie w sektorze publicznym performatywnych metod zarządzania stosowanych w organizacjach biznesowych (Czarnecki 2013; Szwabowski 2014; Szadkowski 2016; Kwiek i in. 2016). Jednocześnie, jak wskazują badania, w polskiej kulturze akademickiej nadal widoczna jest reprodukcja struktur feudalnych (Kościelniak 2015; Sułkowski 2016; Zawadzki 2017), opartych na podporządkowaniu autonomii akademickiej regułom hierarchii decydującej o losie grup defaworyzowanych. To zderzenie neoliberalizmu, zakładającego możliwość swobodnej konkurencji o zasoby w myśl zasad rynkowych (Davies 2014; Styhre 2014), z feudalizmem, promującym relacje folwarczne jako znaczące w rozwoju kariery (Hryniewicz 2012), na polskiej uczelni może skutkować swoistą schizofrenią, szczególnie w grupie młodych naukowców. $Z$ jednej strony muszą oni pracować na nowych, quasi-rynkowych zasadach, a z drugiej - w obliczu braku realnego zwiększenia środków finansowych na naukę - zmuszeni są nadal reprodukować sfeudalizowane, oparte na autorytaryzmie hierarchii relacje społeczne, aby móc w ten sposób konkurować o niewielkie zasoby.

Celem artykułu jest omówienie rezultatów analiz prowadzonych z perspektywy zarządzania humanistycznego nad godnością osób rozpoczynających karierę akademicką w polskiej akademii. W toku wywodu wykorzystuję wyniki badań wstępnych opartych na wywiadach przeprowadzonych z polskimi młodymi naukowcami $(N=7)$, którzy zdecydowali się wyjechać na elitarne stypendia do szwedzkich uczelni. Wybór tej grupy respondentów podyktowany był chęcią poznania opinii wyróżniających się młodych naukowców na temat przemian w polskiej akademii: takich, którzy pracują w uznanych na świecie ośrodkach naukowych i mają możliwość spojrzenia na polski uniwersytet z perspektywy porównawczej.

\section{Neoliberalne transformacje polskiej kultury akademickiej}

Kulturę akademicką możemy rozumieć szeroko jako kulturę organizacyjną uczelni, na którą składają się sieci znaczeń, sensów, wartości i norm stanowiące przedmiot negocjacji i interpretacji ze strony aktorów organizacyjnych i które wpływają na ich sposoby myślenia i działania na uniwersytecie (Dill 1982; Tierney 1988; Becher i Trowler 2001; Silver 2003; Sułkowski 2016; Ylijoki i Henriksson 2017). Na polskim uniwersytecie kultura ta, oparta w dużej mierze na kolegialności i relacjach 
społecznych bazujących na budowaniu zaufania, przekształca się obecnie w kulturę audytu, związaną z kontrolą, sprawozdawczością i konkurencyjnością (Solska 2008; Sułkowski 2016). Zmiana ta stanowi konsekwencję przyjęcia modelu Nowego Zarządzania Publicznego (New Public Management) jako wiodącego w zakresie reform szkolnictwa wyższego i opartego na imitacji w sektorze publicznym rozwiązań biznesowych w celu podniesienia efektywności ekonomicznej usług publicznych (Diefenbach 2009; Arnaboldi, Lapsey i Steccolini 2015). Taki sposób reformowania uczelni na świecie nie jest niczym nowym, widoczny był już od lat 60 . XX wieku - najpierw w Stanach Zjednoczonych, a potem w Europie - gdy rozpoczęła się „rewolucja menedżerystyczna” w szkolnictwie wyższym (Amaral, Meek i Larsen 2003), polegająca na przyjęciu jako wiodącego performatywnego imperatywu zarządzania uniwersytetem (performance management) (Sarrico 2010; ter Bogt i Scapens 2012; Kalio i Kalio 2014).

Zarządzanie performatywne można określić jako paradygmat teorii i praktyk organizacji, oparty na założeniu realizacji idei doskonałości organizacyjnej (organizational excellence), w tym wysokiej wydajności pracy (high performance) (Otley 1999; Williams 2002; Broadbent i Laughlin 2009). W kontekście procesów pracy na uniwersytecie pracownicy naukowi powinni dążyć do wzrostu efektywności swoich działań, mierzonych zdefiniowanymi parametrami ilościowymi oraz przyczyniać się do wzrostu efektywności ekonomicznej i wydajności całej uczelni. Uzasadnieniem dla wprowadzenia takiego sposobu zarządzania jest rosnąca presja na konieczność sprawozdawczości działań uniwersytetu przed otoczeniem zewnętrznym oraz na spełnianie kryteriów doskonałości definiowanych w uczelnianych listach rankingowych (McKelvey i Holmén 2009). Zakłada się zatem zwiększenie kontroli aktorów społecznych spoza uczelni nad oceną jej pracy przy zastosowaniu narzuconych z zewnętrz kryteriów jakości.

Mechanizmy zarządzania performatywnego widoczne są również w Polsce i bazują na stopniowym uzależnianiu karier akademickich od mechanizmów parametryzacji i ilościowej ewaluacji pracy naukowej, których głównym celem jest stopniowe podnoszenie konkurencyjności polskich uczelni w środowisku międzynarodowym. Jak zauważa Emanuel Kulczycki:

Obecnie główną zasadę organizacji i zarządzania nauką oraz szkolnictwem wyższym można scharakteryzować następująco: wszystko ma być możliwe do zmierzenia i oceniania, a na tej podstawie mają być podejmowane skuteczne i - na ile to możliwe zobiektywizowane decyzje dotyczące organizacji i finansowania nauki (Kulczycki 2017: $59-60)$.

Dominacja tej zasady wynika z założenia, że zarządzanie performatywne przyczyni się do wzrostu konkurencyjności wśród pracowników uczelni i do ich rozwoju naukowego, co z czasem pozwoli polskim uniwersytetom dogonić czołówkę na listach rankingowych (Kwiek i in. 2016). Polscy naukowcy stają zatem przed coraz 
większą presją dbania o wynik punktowy swojej pracy, który ma decydujące znaczenie w ocenie parametrycznej jednostek naukowych (Leja 2013).

Innym argumentem za biznesowym modelem zarządzania uczelniami w Polsce jest diagnozowana potrzeba wyeliminowania obecnych w kulturze organizacyjnej polskich uczelni feudalizmu i „relacji folwarcznych” (Hryniewicz 2012; Antonowicz 2015; Kwiek 2016). Eksponują one hierarchię pozycji i tytułów naukowych jako narzędzi służących do podziału zasobów oraz do podejmowania decyzji personalnych. Powoduje to sytuację nierównej gry, uzależnionej od stopnia uprzywilejowania w hierarchii, poszerzając $\mathrm{w}$ ten sposób przestrzeń nierówności pomiędzy pracownikami (Szwabowski 2014). Feudalizm na uniwersytecie nie sprzyja wzrostowi poziomu konkurencyjności uczelni, ponieważ nie promuje innowacyjności, odwagi badawczej i pracowitości (Kościelniak 2015). Co więcej, na co zwraca uwagę David Graeber (2011), feudalizm w oczach właścicieli zasobów często stanowi gwarancję porządku organizacyjnego, w którym podporządkowanie hierarchii nie jest produktem ubocznym relacji folwarcznych, ale celem samym w sobie ${ }^{1}$.

Zastanawiając się nad skutkami wprowadzenia imperatywu zarządzania performatywnego na uczelniach, warto zwrócić uwagę na wyniki różnych badań, które wskazują na pogłębianie się braku równowagi między życiem prywatnym a zawodowym u pracowników, pracoholizm, utratę poczucia własnej wartości, a nawet choroby psychiczne (np. Strathern 2000; Jago 2002; Tuchman 2009; Butler i Spoelstra 2012; Alvesson 2013; Knights i Clarke 2014; Ylijoki i Henriksson 2017). Sprzyja temu poczucie tymczasowości wynikające z niepewnej formy zatrudnienia, a także presja na nieregulowaną konkurencję o zasoby (Craig i in. 2014), prowadząca często do postaw nieetycznych w środowisku naukowym (Macfarlane 2017; Sorokowski, Kulczycki, Sorokowska i Pisanski 2017).

Na takie negatywne zjawiska na uniwersytecie szczególnie wydają się być narażone osoby rozpoczynające karierę akademicką. Jak zauważają niektórzy badacze (Laudel i Gläser 2008; Ylijoki i Henriksson 2017), młodzi naukowcy na wczesnym etapie kariery naukowej stanowią najbardziej wrażliwą grupę pracowników nauki, doświadczającą szczególnej niepewności zatrudnienia, będącą pod presją walki o autonomię, niezależność i legitymizację ze strony środowiska. Neoliberalna ideologia, jak wskazują krytycy jej implementacji w uniwersytecie (Prasad 2013; Knights i Clarke 2014; Malsch i Tessier 2015; Raineri 2015), może wzmacniać tendencje upolitycznienia tożsamości młodych naukowców, które polega na zawłasz-

${ }^{1}$ Na osobne rozważania i badania zasługuje propozycja Davida Graebera (2011), aby na relacje feudalne patrzeć z perspektywy pojęcia honoru definiowanego jako nadmiar godności. W tym kontekście warto byłoby np. zadać pytanie, czy „samodzielni” pracownicy polskiego uniwersytetu nie kreują czasem relacji folwarcznych, aby chronić (w ich mniemaniu) młodszych pracowników przed zgubnymi skutkami neoliberalizmu i budować w ten sposób swój honor w oczach innych? Autor dziękuje serdecznie anonimowemu recenzentowi tego tekstu za ten przełomowy trop. 
czaniu sfery niepewności przez ideologie proponujące jej niwelowanie poprzez promowanie określonych postaw i działań społecznych. Na przykład presja rywalizacji na neoliberalnym uniwersytecie sprzyja wzrostowi poczucia niepewności w miejscu pracy, co może skutkować akceptacją postaw konformistycznych względem decyzji i poglądów właścicieli pożądanych zasobów. Rodzi to problem tworzenia monokultur na uczelniach, skutkujących jednomyślnością i brakiem autonomii w pracy naukowej (Morrissey 2015). Poczuciu niepewności sprzyja faza liminalna (Turner 1966) w rozwoju życiowym i zawodowym młodych naukowców, polegająca na doświadczaniu momentu przejściowego pomiędzy rolą młodego adepta nauki a naukowca posiadającego legitymizację środowiska (Szkudlarek 2010; Beech 2011).

Faza liminalna zdaje się również charakteryzować młodych polskich naukowców rozpoczynających karierę akademicką. Jak pokazują badania Marka Kwieka (2016) i Dominika Antonowicza (2015), coraz bardziej zdają sobie oni sprawę z konieczności gry na nowych zasadach biznesowych, koniecznych w ich mniemaniu do legitymizacji swojego statusu jako pracowników nauki. Jednocześnie nadal twierdzą, że muszą brać pod uwagę relacje feudalne i znajomości, mające ich zdaniem spory wpływ na przebieg karier akademickich w Polsce. Jak zauważa Marek Kwiek:

[...] część respondentów jest przekonana o tym, że o kolejnych stopniach akademickich decydują kontakty towarzyskie, a nie dorobek naukowy. Osiągnięcia naukowe nie są niezbędne, a praktyka pokazuje, że duża część przyznawanych stopni naukowych nie wiąże się bezpośrednio z nauką, a z czymś, co respondenci określają mianem „dobrego ulokowania” w nauce (Kwiek 2016: 443).

Być może to właśnie ta nierówna, feudalno-neoliberalna gra skutkuje zwiększonym obciążeniem pracą i chronicznym brakiem czasu na badania naukowe w grupie osób ze stopniem doktora, na co wskazują autorzy raportu badawczego „Nie zostaje mi czasu na pracę naukową,, przygotowanego przez inicjatywę Nowe Otwarcie Uniwersytetu (Kowzan, Zielińska Kleina-Gwizdała i Prusinowska 2016; por. Szenajch, Małecka i Suwada 2013). Respondenci wskazują tam na problem przeciążenia pracą, braku równowagi między życiem prywatnym a zawodowym, rosnącego stresu czy coraz większego poczucia izolacji. Podobne odczucia mają polscy doktoranci, którzy, jak pokazują badania Anny Koli (2016), borykają się dodatkowo z problemem fikcji kształcenia na studiach trzeciego stopnia. Jednocześnie trzeba zauważyć, że młodzi pracownicy nauki często widzą w neoliberalnych zasadach gry szansę na „normalność”, polegającą na desubiektywizacji ich osiągnięć i karier, oraz zwiększenie przejrzystości i sprawiedliwości w procesach pracy poprzez odejście od relacji feudalnych opartych na znajomościach (Kwiek 2016). Jak to zawieszenie między feudalistycznymi i neoliberalnymi warunkami pracy może wpływać na godność osób rozpoczynających karierę naukową w Polsce? 


\section{Godność w miejscu pracy}

Z perspektywy filozoficznej godność pozwala człowiekowi na pełną realizację jego człowieczeństwa i może być rozpatrywana przynajmniej z dwóch punktów widzenia (Rosen 2012). Z jednej strony godność nie wymaga żadnych warunków do spełnienia - przynależy każdemu człowiekowi z samego powodu bycia człowiekiem (Kant 1953). Z drugiej strony godność to potencjalność, którą można aktualizować, a więc doskonalić w działaniu, ale która może też być ograniczana (Wojtyła 1969; Düwell, Braarving, Brownsword i Mieth 2014). To drugie ujęcie przyjmuje się w ramach badań prowadzonych w nurcie zarządzania humanistycznego (Batko 2013; Zawadzki 2014; Nierenberg i in. 2015; Dierksmeier 2016), w którym człowiek i jego godność stanowią najwyższe dobro $\mathrm{w}$ organizacji i wymagają ochrony przy wykorzystaniu procesów zarządzania (Hodson 2001; Prawelska-Skrzypek 2007; McCloskey 2010; Kostera i Pirson 2017).

Godność z perspektywy zarządzania humanistycznego nie podlega ani relacjom wymiany, ani regułom efektywności ekonomicznej - jest niezbywalnym składnikiem człowieczeństwa, aczkolwiek mogącym podlegać ograniczaniu lub wzmacnianiu (Lucas 2015). Rolą badaczy organizacji i zarządzania jest próba zrozumienia, jak dane miejsce pracy i związane z nim procesy zarządzania mogą wpływać na pracowników i ich godność: czy jest to wpływ umożliwiający realizację etycznych aspektów pracy (w tym godności), czy raczej wpływ negatywny, hamujący możliwość rozwoju potencjału humanistycznego organizacji?

Interesującej odpowiedzi na powyższe pytania udziela Randy Hodson (2001), który wyróżnia i systematyzuje procesy organizacyjne prowadzące zarówno do zaprzeczenia godności, jak i do jej ochrony w miejscu pracy. Negatywnie na ludzką godność w organizacji wpływają jego zdaniem takie style zarządzania ludźmi, które prowadzą do nadużyć względem pracowników (Hodson 2001). Traktowanie pracowników jako zasobów i środków do osiągnięcia z góry narzuconych celów organizacyjnych może skutkować utratą przez nich autonomii, a także szacunku dla wykonywanej pracy. Niehumanitarne zarządzanie eliminuje z przestrzeni relacji społecznych w organizacji możliwość dążenia do konsensusu - bazuje na uznaniu konformizmu jako pożądanej wartości organizacyjnej, a także na stosowaniu kar wobec tych, którzy nie zgadzają się na proponowane rozwiązania organizacyjne lub nie spełniają narzuconych norm wydajnościowych. Jak pokazują inni badacze, atak na godność pracownika widoczny jest w takich partykularnych sytuacjach $\mathrm{w}$ organizacji, jak: słowne upokarzanie (Stuesse 2010), negatywne stygmatyzowanie (Otis 2008), praca pod przymusem (Crowley 2012) czy nieczułość na potrzeby pracowników (Gunn 2011). W miejscu pracy, w którym widoczne są takie patologie, nagradza się uległość i pracoholizm, które negatywnie wpływają na możliwość ochrony godności (Hicks 2016). 
Tabela 1. Procesy ochrony i zaprzeczania godności w miejscu pracy

\begin{tabular}{|c|c|}
\hline Procesy ochrony godności & Procesy zaprzeczania godności \\
\hline Zdolność do stawiania oporu & Nadużywanie władzy \\
Obywatelstwo organizacyjne & Niehumanitarne zarządzanie \\
Tworzenie niezależnego systemu znaczen & Przepracowanie \\
Rozwój relacji grupowych & Ograniczanie autonomii \\
\hline
\end{tabular}

Źródło: opracowanie własne na podstawie Hodson 2001.

Z kolei ochrona godności w organizacji wymaga ciągłego dbania o humanistyczny wymiar warunków pracy, w tym szczerego respektu ze strony współpracowników i osób sprawujących władzę - takiego, który pozwoli na szacunek dla własnej i cudzej pracy, stanowiąc impuls do poczucia spełnienia i dalszego rozwoju (Karlsson 2012). Warunkiem koniecznym dla rozwoju szacunku wobec siebie i innych jest określony poziom autonomii, pozwalający na niezależną kontrolę swoich działań organizacyjnych. Autonomia kształtuje się na bazie możliwości bycia zauważanym i wysłuchiwanym, a także deliberatywnej komunikacji organizacyjnej, w której istnieje możliwość wyrażania konstruktywnej krytyki bez ryzyka bycia upokorzonym, nawet w przypadku braku posiadania przekonujących argumentów (Sayer 2007).

W sytuacjach zagrażających godności, zdaniem Hodsona, należy podjąć działania ochronne, z których najważniejsze to niepoliczalne akty mikrooporu pracowników wobec kierowanych w stosunku do nich nadużyć (Hodson 2001). Mogą one, jak wskazują inni badacze, przybrać formę ukrytą - w postaci cynizmu bazującego na wewnętrznej niezgodzie na zastane warunki (Fleming i Spicer 2007) lub bardziej jawną - związaną z niezgodą na niekorzystne decyzje, absencją w pracy, organizacją strajków czy ostatecznie z odejściem z organizacji (Stuesse 2010). Innymi formami ochrony godności w koncepcji Hodsona są: budowanie demokratycznych relacji ze współpracownikami opartych na zaufaniu i szacunku, a także tworzenie alternatywnego, niezależnego systemu znaczeń, który pozwala na krytyczny dystans wobec patologii organizacyjnych. Godność chroniona może być również dzięki obywatelskim działaniom mającym na celu ochronę dobra współpracowników (Hodson 2001; Bolton 2007).

\section{Godność na polskim uniwersytecie - wyniki badań wstępnych}

Prezentowane w dalszej części tekstu badania są próbą analizy kategorii godności w kontekście warunków pracy na uniwersytecie. Ich głównym celem jest próba zrozumienia, jak zmieniająca się kultura akademicka na polskiej uczelni wpływa na godność osób rozpoczynających karierę akademicką - młodych polskich na- 
ukowców i doktorantów. W badaniach przyjęto jakościową metodologię opartą na wykorzystaniu techniki wywiadu pogłębionego, nieustrukturyzowanego i niestandaryzowanego, co było uzasadnione chęcią pogłębionego zrozumienia badanego fenomenu, a także potrzebą budowania relacji zaufania z respondentami (Kostera 2003; Fontana i Frey 2009). W badaniach przyjęto perspektywę narracyjną w zarządzaniu (Czarniawska 1997; 2004), zgodnie z którą organizacje stanowią miejsce nieustannego, kolektywnego konstruowania przez ludzi narracji, które nadają sens ich działaniom. Interpretacja tych narracji w procesie badawczym pozwala na pogłębione zrozumienie znaczeń i sensów, jakie respondenci nadają swojemu miejscu pracy (Elliot 2005; Ylijoki 2005). Drażliwy temat warunków kształtujących pracę młodych naukowców wymagał zagwarantowania anonimowości i poufności danych.

Dobór respondentów miał charakter celowy: w okresie od stycznia do czerwca $2015 \mathrm{r}$. przeprowadzilem siedem wywiadów pogłębionych z polskimi pracownikami nauki ze stopniem doktora - „postdok” $(N=3)$ oraz doktorantami - „dok” $(N=4)$, wszyscy do 35. roku życia, pracującymi w różnych dyscyplinach nauki (społeczne: 4 osoby, humanistyczne: 1 osoba, ścisłe: 1 osoba, przyrodnicze: 1 osoba), którzy $\mathrm{w}$ trakcie prowadzenia wywiadów przebywali na krótkoterminowych stypendiach badawczych na szwedzkich uniwersytetach. Uzasadnieniem wyboru tej grupy respondentów była przede wszystkim chęć poznania opinii o warunkach pracy w polskim uniwersytecie ze strony wyróżniających się młodych polskich badaczy, którzy aktywnie funkcjonują w środowisku międzynarodowym, mają stypendia w uznanych na świecie ośrodkach naukowych i mogą dostarczyć ciekawych i być może bardziej odważnych narracji z perspektywy zagranicznych doświadczeń. Polska kultura akademicka badana była do tej pory głównie z perspektywy respondentów pracujących w polskich ośrodkach akademickich (Antonowicz 2015; Kwiek 2016), spojrzenie ze strony osób pracujących poza granicami kraju może stanowić ich wartościowe uzupełnienie.

Każdy wywiad trwał około dwóch godzin i miał formę swobodnej konwersacji, ale ukierunkowanej na konkretny cel - była nim chęć poznania opinii respondentów na temat warunków pracy na polskim uniwersytecie. Zbieranie i interpretacja danych odbywały się w myśl logiki abdukcji (nazywanej w literaturze „logiką odkrycia”; Czarniawska 2014) - zamiast konwencjonalnego gromadzenia danych, z których wnioski można indukować, zastosowana została strategia krążenia pomiędzy terenem badawczym (wywiad) a biurkiem (transkrypcja i analiza) i z powrotem, w celu ciągłego nasycania wyłaniającej się teorii. Wywiady były analizowane i kodowane przez badacza, który poszukiwał kategorii analitycznych bazujących na powtarzających się wątkach w wypowiedziach. Wyłonione kategorie dotyczą zatem wątków, które przewijają się wielokrotnie w różnych wypowiedziach, tworząc w ten sposób zarys opinii respondentów dostępny na poziomie kultury akademickiej, a nie jedynie pojedynczych narracji. 
Ostatecznie możliwe było wydobycie takich kategorii, jak: pracoholizm, ograniczanie autonomii, nadużycia władzy, zachowania nieetyczne i niechęć do przebywania w miejscu pracy, które zinterpretowano jako cechy wpływające negatywnie na godność w organizacji. W wypowiedziach respondentów trudno było doszukać się opisu takich zjawisk, które można by zinterpretować w kategoriach ochrony godności, aczkolwiek na uwagę zasługuje wyraźne wskazanie na wskaźniki punktowe jako narzędzie nadawania sensu pracy na uczelni. Co ciekawe, niezależnie od posiadanego statusu (doktorant/doktor) oraz dyscypliny nauki (humanistyczne, społeczne, ścisłe, przyrodnicze) respondenci odnosili się do polskiego uniwersytetu w swoich wypowiedziach w sposób krytyczny i pesymistyczny, ale odniosłem wrażenie, że przedstawiciele nauk ścisłych i przyrodniczych w swoich opowieściach o pracy na polskiej uczelni cechowali się mniejszym krytycyzmem.

Z racji niewielkiej próby wyniki należy traktować jako wstępny pilotaż, który pozwoli naświetlić zagadnienia problemowe konieczne do dalszej eksploracji, stanowiąc dodatkowe spojrzenie na już zbadane przemiany kultur akademickich na polskim uniwersytecie (Antonowicz 2015; Kwiek 2016; Sułkowski 2016). Warto również podkreślić, że dobór respondentów mógł wpłynąć na prezentowane wyniki badań w dwojaki sposób: z jednej strony wyjazd zagraniczny i praca na zagranicznym uniwersytecie mogą sprzyjać negatywnym opiniom na temat macierzystych uczelni w Polsce. Z drugiej strony dystans wynikający z emigracji może być motywatorem pobudzającym do wyrażania bardziej odważnych i szczerych opinii, wnoszących dodatkowy wkład w rozumienie warunków pracy na polskich uczelniach (Zielińska i Kowzan 2016).

\subsection{Pracoholizm}

Ochrona godności w miejscu pracy oznacza poszanowanie dla życia osobistego pracownika i zapewnienie mu możliwości realizacji satysfakcjonującej równowagi między życiem rodzinnym a zawodowym. Praca ponad siły i możliwości uderza negatywnie w godność, reifikuje ją i obarcza jarzmem niepotrzebnego i przeszkadzającego elementu w uzyskiwaniu jak najlepszej wydajności. Uczucia, emocje, relacje rodzinne - a więc zjawiska stanowiące o niepowtarzalności człowieka i warunkujące jego godność - w warunkach nadmiaru pracy tracą na znaczeniu (Hodson 2001; Bolton 2007; Ylijoki 2010).

Zdaniem respondentów obecne zmiany na polskich uczelniach rodzą poczucie, że praca nigdy nie jest zakończona - zawsze można zrobić coś więcej, aby osiągnąć lepszy rezultat, co wynika z braku jasnych definicji oczekiwań wobec pracowników oraz braku kryteriów, które pozwoliłyby im zaplanować karierę naukową. Presja na nieustanną pracę potęgowana jest brakiem poczucia bezpieczeństwa wynikającego z zatrudnienia na umowy czasowe. Respondenci odczuwają konieczność ciągłego dążenia do doskonałości - pracują w myśl reguły, że im więcej zrobią, tym zwiększą 
prawdopodobieństwo pozostania na uczelni (doktoranci) lub przedłużenia zatrudnienia (osoby ze stopniem doktora). Nie mając jednak poczucia, że reguły gry dotyczące sukcesu czy awansu są jasno zdefiniowane, pracują najwięcej, jak mogą. Jak zauważa jedna z respondentek:

[...] faktycznie jest jakiś taki, mam wrażenie, strach też podsycany trochę przez dziekana i wladze, który wlaśnie dotyczy publikacji, grantów, i to wszystko w takim, podany $w$ taki sposób, że no, jeżeli nie będziemy mieć grantów, publikacji tudzież studentów, to wlaśnie to wszystko się rozleci i stracimy pracę itd. (postdok 1, n. społeczne).

Zdaniem respondentów, co niejednokrotnie podkreślali w wypowiedziach, pracoholizm opiera się na życiu w niepewności, która z kolei wynika z braku jasnych kryteriów określających poziom jakości wykonywanej pracy na uczelni i z poczucia konieczności rywalizacji z innymi. Ich zdaniem wprowadzony system punktowej ewaluacji wyników nie rozwiązuje tych problemów, a raczej je wzmacnia poprzez dalsze rozwijanie relacji feudalnych, na które miał stanowić remedium. Mowa tu o problemie obarczania odpowiedzialnością za rozwój jednostek naukowych przez punktowane osiągnięcia naukowe tylko młodszych pracowników, przy bezkarności w tym względzie starszych kolegów i koleżanek. Pogłębia to zdaniem respondentów odwieczny problem faworyzowania i defaworyzowaniu młodszych osób przez samodzielnych pracowników nauki. Respondenci wskazują również na poczucie bezsilności w zakresie możliwości dokonania realnych zmian w polu ich pracy.

\subsection{Ograniczanie autonomii}

Autonomia w pracy naukowo-dydaktycznej oznacza wolność w zakresie nauczania i prowadzenia badań naukowych, które nie powinny być ograniczane nieuzasadnioną ingerencją wynikajacą ze zbytniej kontroli czy presji zewnętrznej (Lynch i Ivancheva 2015). Autonomia pozwala na podejmowanie tematów badawczych zgodnie z osobistymi zainteresowanimi badacza, na swobodne dyskutowanie wyników badań w gronie innych badaczy i studentów, a także publikowanie prac bez kontroli cenzorskiej czy autocenzorskiej. Autonomia akademicka to również możliwość swobodnego wyrażania swoich potrzeb przez pracowników, doktorantów i studentów oraz praca na bazie wspólnie uzgodnionych i obopólnie przestrzeganych, jawnych warunków. Tak rozumiana autonomia jest warunkiem koniecznym realizacji godności pracowniczej na uniwersytecie, która bazuje na możliwości autonomicznego gospodarowania własną wolnością (Hodson 2001).

Wątek ograniczania wolności pojawia się szczególnie w wypowiedziach przedstawicieli nauk społecznych i humanistycznych. Podkreślają oni problem spychania na nich obowiązków administracyjnych i dydaktycznych, jak i traktowania ich przez pracowników samodzielnych jedynie jako zasobu koniecznego do spełnienia 
wymogów pozwalających na uzyskanie tytułów naukowych. Jednocześnie dominuje świadomość, że przetrwanie na uczelni zależy od umiejętności zaakceptowania braku autonomii:

Natomiast, no tak jak większości przypadków no to jest to takie pewne nadużycie związane z wykorzystywaniem doktorantów do tatania niedoborów kadrowych $w$ jednostkach naukowo-dydaktycznych $w$ Polsce, no bo do tego się sprowadza (dok 1, n. społeczne).

Powstała $\mathrm{w}$ ten sposób sprzeczność pomiędzy wymaganiami doskonałości akademickiej ze strony makrodyskursu, którym się posługuje dana instytucja czy otoczenie zewnętrzne, a realnymi warunkami pracy rodzi dysonans i zagubienie. $\mathrm{Z}$ jednej strony respondenci czują presję spełniania wymogów międzynarodowej normy doskonałości badawczej i często akceptują ją jako pożądaną drogę rozwoju, z drugiej - muszą borykać się z patologiami polityki wewnątrzuczelnianej, godząc się na utratę wolności przez instrumentalne i feudalne działania ze strony pracowników usytuuowanych wyżej w hierarchii akademickiej czy strukturach władzy. Jak zauważa jedna z respondentek:

[...] to znaczy, że no co prawda zwolnit się etat, ale to do końca roku akademickiego to przecież nie warto zatrudniać nikogo, a przecież to dziekan tak naprawdę to nie jest $w$ gestii zakładu czy instytutu, tylko że to dziekan będzie decydowal, więc jakby ten etat wraca do puli dziekańskiej, a w ogóle to dziekan nie chce tego etatu zapetniać, bo chce zaoszczędzić i takie jakieś strasznie to długo trwato, takie wtaśnie dosyć wymijające informacje, a ja nie bardzo jakoś umiatam to chyba wtedy zinterpretować jako odmowę, czy nawet nie tyle odmowę, co taka, no jakoś tak, odmowe (postdok 1, n. społeczne).

Nieprzejrzyste i niedemokratyczne reguły zatrudnienia i awansów to najczęściej wymieniane przez respondentów skutki kultury folwarcznej na polskiej uczelni, które tworzą schizofreniczną przestrzeń w zderzeniu z międzynarodowymi normami rzetelności i doskonałości naukowej.

\subsection{Nadużycia władzy}

Z perspektywy rozwoju godności w miejscu pracy procesy władzy powinny wspierać rozwój humanistycznego wymiaru organizacji poprzez tworzenie możliwości dla samorozwoju na mocy sprawiedliwej dystrybucji decyzji i zasobów (Hodson 2001; Karlsson 2012). Władza często jednak służy do realizacji partykularnych interesów, co idzie w parze, szczególnie w organizacjach (post)biurokratycznych (Batko 2013), z atakiem na ludzką godność przez kreowanie autorytarnych relacji społecznych mających na celu podporządkowanie osób znajdujących się niżej w hierarchii organizacyjnej. 
Na problem nadużyć władzy na uniwersytecie zwrócili uwagę również moi respondenci. Jedna z doktorantek użyła sformułowania „kult dostojników” (dok 2, n. humanistyczne) na określenie polskiego środowiska promotorów prac doktorskich - osób z habilitacją i profesurą, podkreślając w ten sposób ich nietykalność, konieczność poddaństwa względem ich woli w celu przeżycia oraz ukazując ich napuszenie, przyjmujące niekiedy groteskowe formy z powodu często miernej jakości ich dorobku naukowego. Napuszone dostojeństwo kreuje problem autorytaryzmu w przestrzeni komunikacji na uniwersytecie (Witkowski 2011) i zmusza do naśladownictwa cudzych poglądów, często tylko z powodu posiadanego tytułu czy miejsca $w$ hierarchii organizacyjnej zajmowanego przez ich wyrazicieli. Zdaniem respondentów autorytaryzm starszych pracowników nauki idzie w parze z posiadaniem hegemonicznej władzy i niesprawiedliwym prawem decydowania o podstawowych potrzebach młodych pracowników naukowych i doktorantów, którzy stają się, jak zauważa jeden z respondentów, „ostatnimi w łańcuchu pokarmowym” (dok 1, n. społeczne).

Bycie „ostatnim w łańcuchu pokarmowym” wiąże się również z lekceważącym stosunkiem samodzielnych pracowników, którzy nie przejawiają zainteresowania badaniami prowadzonymi przez młodych pracowników naukowych i doktorantów. Mało tego, zdaniem respondentów w społeczności młodych nie ma kultury dyskusji - dominuje indywidualny tryb pracy ukierunkowany na zdobywanie punktów:

Nie ma tego $w$ Polsce i to myślę, że by bardzo polepszyło, miałam jakieś tam dyskusje, natomiast no, pewnie jakbym miała więcej, to może nie wiem, może więcej bym osiagnęła, może bym miała większq wspótpracę, więc no, myślę, że to by mogło trochę tak jakby, taki przymus, że musisz tam isśc coś powiedzieć, na przykład w moim zakładzie zawsze było tak, że co miesiąc każdy z pracowników musiał występować, nie? (postdok 2, n. przyrodnicze).

Ewentualna współpraca i zainteresowanie zaczyna się dopiero w momencie, gdy jedna ze stron ma do zaproponowania udział w grancie badawczym. Jak podsumowuje tę sytuację jedna z doktorantek: „w Polsce właściwie ludzie tylko gonią za pieniądzem i udają intelektualistów" (dok 3 , n. społeczne). Tak mocne opinie wcale nie były odosobnione w badaniach i wskazują na spory problem świadomości występowania rytualizacji pozoru pracy naukowej w Polsce.

\subsection{Zachowania nieetyczne}

Postawy etyczne warunkują możliwość rozwoju godności w organizacji. Kultura organizacyjna oparta na wartościach i normach promujących etyczność działań społecznych będzie wspierała rozwój wrażliwości i wyobraźni humanistycznej i w konsekwencji rozwój mechanizmów wspierających ochronę godności (Hodson 2001; Zawadzki 2014). 
Moi rozmówcy często nawiązywali w swoich wypowiedziach do nieetycznych sposobów stosowanych przez środowisko naukowe w celu spełniania norm systemu zarządzania performatywnego. W wypowiedziach pojawia się wątek kartelu intelektualnego opartego na znajomościach i wzajemności cytowań, a także temat fikcyjnego współautorstwa tekstów naukowych (Brzeziński 2015; Kulczycki 2016; Macfarlane 2017). Symptomatyczna jest w tym kontekście wypowiedź jednej z respondentek, która stwierdziła, że dla niej jedną z szans na przetrwanie na uczelni jest współautorstwo w publikacjach pisanych przez bardziej doświadczonego i obytego w środowisku męża (postdok 2, n. przyrodnicze). Jak z kolei zauważa inna respondentka:

[...] ja nie znoszę pracować pod presją, a to jest praca pod presją, że musisz wyprodukować jakąś tam liczbę czegoś tam i najlepiej jeszcze właśnie, o, wiesz dlaczego? Teraz już mi się... teraz mi się sformutowat konkretny argument $w$ głowie, na przykład presja cytowań. Niestety tak jest, że ludzie, że wytwarza się coś takiego jak citation network „zacytuj mnie, a ja zacytuję ciebie”. To nie jest potrzebne, to nie jest wtaściwe, to, oczywiście nie żyjemy widealnym świecie, ale to nie powinno być... tak nie powinno być (postdok 3 , n. społeczne).

Co prawda sama sieć cytowań nie musi być klasyfikowana jako działalność nieetyczna, ponieważ może wiązać się ze współpracą określonej grupy badaczy nad danym problemem w nauce. Wątpliwości etyczne mogą jednak budzić spółdzielnie cytowań, opierające się na wzajemnym załatwianiu korzyści w przestrzeni iluzji pracy naukowej.

\subsection{Niechęć do przebywania w miejscu pracy}

Kiedy środowisko pracy staje się przestrzenią niekorzystnie wpływającą na rozwój człowieka, może dochodzić do działań eskapistycznych mających na celu ochronę godności, związanych z postępującą absencją, a w konsekwencji z odejściem z pracy (Hodson 2001; Stuesse 2010). Moi respondenci często wskazują w swoich wypowiedziach na problem niechęci do przebywania na uczelni. Jak mówi jedna z respondentek:

[...] mianowicie przynajmniej u mnie na wydziale jest generalnie kultura dnia codziennego polega na tym, żeby jak najmniej być na uczelni (postdok 1, n. społeczne).

Jedną z przyczyn tego stanu rzeczy wydaje się wszechobecność konfliktów interpersonalnych, które negatywnie wpływają na atmosferę uczelni. W tym kontekście rozmówcy dostrzegają problem reprodukcji konfliktów mających miejsce wśród samodzielnych pracowników naukowych, którzy są lub byli ich promotorami, negatywnie wpływających na relacje między doktorantami a młodymi pracownikami. Jak wskazuje jeden z doktorantów: 
[...] jest ten problem gdzie takich napięć personalnych pomiędzy profesorami u nas $i$ to $w$ pewien sposób rzutuje na relacje między doktorantami, tak, to znaczy, mimo że to brzmi trochę kuriozalnie, to doktoranci z tych różnych zakładów... no z pewną, $z$ dużą dozą nieufności do siebie podchodzą, tak? (dok. 1, n. społeczne).

Konflikty i napięcia rozpatrywane są przez respondentów jako naturalne elementy pracy na uniwersytetach, z którymi trzeba się liczyć w rozwoju kariery. Jak zauważa ten sam respondent:

[...] $w$ sensie pewnie sa takie chwile, $w$ których tam chtopcy się trochę bardziej przepychaja, a sq takie, $w$ których trochę mniej. I pewnie lepiej się bronić $w$ tej, w której się trochę mniej przepychają (dok 1, n. społeczne).

Konflikty wpływają negatywnie na atmosferę w miejscu pracy. Między innymi stąd wynika podkreślana czasem przez respondentów konieczność przyjmowania logiki przetrwania na uniwersytecie. Bazuje ona na działaniach mających sprawiać wrażenie, że jest się potrzebnym pracownikiem, przy jednoczesnej pracy jak najmniejszym kosztem. Wpływ na niechęć do przebywania na uczelni ma również słaba infrastruktura, która nie pozwala czuć się komfortowo:

[...] bardzo się mato staram być $w$ pracy, bo nie mam też tak naprawdę warunków tam do pracy, znaczy jest... jesteśmy strasznie sttoczeni, nie ma na przykład nigdzie tam możliwości, żeby coś zjeść czy żeby gdzieś tam odpoczać, wobec tego jakby też się nie dziwię i sama tak robię, żeby tam nie przebywać. No, ale nawet jeżeli jesteśmy jakoś tam razem, gdzieś się spotykamy czy $w$ czasie jakiejś przerwy, to takich dyskusji praktycznie merytorycznych nie ma (postdok 1 , n. społeczne).

Warto zauważyć, że przedstawiciel nauk ścisłych jako jedyny w sposób pozytywny odniósł się do motywacji przebywania na uczelni:

[...] wierzy się $w$ ludzi mlodych, $w$ sensie, że nie narzuca im się z góry ram sztywnych, tylko no zawsze jest jakieś prawdopodobieństwo, że jeżeli zwołamy trochę ludzi, tak, i oni będa losowo coś robić, no to coś z tego wyjdzie, prawda? No więc powiedzmy, że tutaj zwohuje się ludzi nielosowo, ale powiedzmy jakichś tam o określonych parametrach, no i daje im się szanse, tak, no i jeżeli to sa inżynierowie, którzy maja predyspozycje do tego, żeby coś wymyślić, no to jest duża szansa, że to wymyśla (dok 4, n. ścisłe).

Wpływ na pozytywną opinię miała niewątpliwie dobra sytuacja w miejscu pracy respondenta, związana z bardzo dobrą infrastrukturą badawczą, niewielką liczbą doktorantów w akademii i wysokimi stypendiami, pozwalającymi na niepodejmowanie dodatkowego zatrudnienia. Być może warunki pracy zapewnione przedstawicielom nauk ścisłych w Polsce mogłyby stanowić punkt odniesienia dla proponowanych zmian w innych dziedzinach nauki. 


\subsection{Punkty jako sens pracy}

Dostrzeganie sensu w wykonywanej pracy to warunek konieczny czerpania satysfakcji z pracy, która pozwala na szacunek dla siebie i możliwość rozwoju godności (Hodson 2001; Hicks 2016). Pomimo ogólnej niechęci respondentów do neoliberalnych zmian na polskich uczelniach według kilku z nich system punktowy pozytywnie wpływa na ich poczucie spełnienia w pracy. Jak pokazują badania na świecie, punkty przypisane czasopismom, a także te będące wynikiem ewaluacji osiągnięć naukowych to czasami jeden z nielicznych namacalnych dowodów na sens pracy na uczelni (Barry, Chandler i Heather 2001; Smeenk, Teelken, Eisinga i Doorewaard 2009; Decramer, Smolders i Vanderstraeten 2013). Widać to również $\mathrm{w}$ wypowiedziach moich respondentów oraz w bardziej reprezentatywnych badaniach Marka Kwieka (2016). Powtarzający się tam pogląd młodych naukowców na temat pozytywnej korelacji między sensem pracy a ilościowym systemem ewaluacji może wskazywać na krytyczny stosunek do dotychczasowego systemu oceny osiągnięć naukowych, oparty często na arbitralnej ocenie środowiskowej podporządkowanej regułom feudalnym. Ambiwalentny stosunek do ewaluacji punktowej dobrze odzwierciedla wypowiedź jednej z moich respondentek:

Natomiast teraz, że też jest jakaś taka podejrzliwość pomiędzy pracownikami nawzajem, prawda, co kto zrobit, gdzie opublikowat i czy będzie miał więcej punktów, czy mniej. I to, to jest oczywiście niedobre, natomiast ja cały czas dosyć, znaczy jakoś ten system do mnie przemawia, o tyle że mam wrażenie, że jeśli chodzi o to, co ja robię i to, że to, co ja robię, jest bardzo odległe od jakby profilu wydziału, to to jest dla mnie jedyny taki namacalny dowód tego, że to, co ja robię, ma sens (postdok 1, n. społeczne).

Z jednej strony konstatacja ta wskazuje na zniechęcenie dotychczasowymi niejasnymi regułami gry i świadczy o pozytywnym nastawieniu do wartości liczbowych jako nadających sens pracy naukowej, z drugiej jednak dowodzi braku umiejętności dostrzeżenia patologii systemu punktowego, które zauważają inni respondenci przywoływani wcześniej.

\section{Zakończenie}

Polski uniwersytet to ciekawe pole badawcze ze względu na zderzenie neoliberalnych reform z głęboko zakorzenionym feudalizmem w strukturach władzy. Zdaniem respondentów rozwiązania quasi-rynkowe często pogłębiają jedynie problemy, na które w teorii miały stanowić remedium - szczególnie feudalizmu, braku sprawiedliwości i hegemonii władzy opartej na „kulcie dostojników”. Moi rozmówcy czu- 
ją się traktowani jak „ostatni w łańcuchu pokarmowym” - czekający z pokorą, aż ktoś ich doceni, porozmawia lub przyzna dodatkowe finansowanie czy miejsce do pracy. Znajdujący się w napiętej fazie przejścia pomiędzy byciem „samodzielnym” a „niesamodzielnym” naukowcem, a także pomiędzy starym systemem feudalnym a nowym systemem neoliberalnym, młodzi przyjmują często postawy konformistyczne, pozwalające im na przetrwanie. Brak autonomii działania i decyzyjności w zakresie polityki uczelni, lekceważący stosunek ze strony samodzielnych pracowników naukowych z habilitacją i profesurą, pracoholizm będący wynikiem presji na zdobywanie punktów oraz skutkiem cedowania niewygodnych i „nieopłacalnych” zadań administracyjnych i dydaktycznych, stypendia i pensje niepozwalające na finansowe przeżycie, konieczność działania według logiki ultrakonformizmu jako logiki przetrwania - to tylko niektóre patologie polskich uczelni, o których mówili moi respondenci, skutkujące utratą godności akademickiej.

Zastanawiając się nad przyczynami negatywnych opinii, warto wziąć pod uwagę ciekawą konstatację Marka Kwieka (2016), że młodzi polscy badacze - w odróżnieniu od swych zachodnich koleżanek i kolegów - nie są zainteresowani prowadzeniem badań. W moim odczuciu może to wynikać z jednej strony z postępującej niechęci do relacji feudalnych i strukturalnej reprodukcji czasu pracy ukierunkowanego głównie na dydaktykę, z drugiej - ze świadomości patologii, jakie generuje neoliberalny system punktowo-wskaźnikowy, nastawiony na drapieżną konkurencyjność i wcale niegwarantujący wzrostu jakości badań naukowych czy zwiększenia poziomu merytokracji na uczelniach (Magala i Zawadzki 2017). Jak piszą dosadnie David Knights i Caroline Clarke (2014), marzenie o byciu doskonałym naukowcem potrafiącym spełniać neoliberalne kryteria efektywności jest iluzją prowadzącą co najwyżej do konstrukcji prekarnej tożsamości, która rodzi dysonans między znaczeniem aspiracji zawodowych a sensem pracy. Co prawda warto też wziąć pod uwagę konstatację Kwieka, że negatywne opinie na temat systemu punktowego wśród młodych polskich naukowców to wynik obawy o stabilność zatrudnienia (Kwiek 2016), mimo to sądzę, że przyczyny mogą być o wiele bardziej złożone, łącznie ze wspomnianą obawą o jakość dorobku naukowego czy etyczność w miejscu pracy (Zawadzki 2017).

Zastanawiając się nad możliwością doskonalenia warunków pracy doktorantów i młodych pracowników nauki w Polsce, warto wziąc pod uwagę propozycję Randy'ego Hodsona, którego zdaniem podstawową formą ochrony godności w miejscu pracy są niepoliczalne akty mikrooporu pracowników wobec stosowanych względem nich nadużyć (Hodson 2001). Idąc tropem Hodsona, w przypadku polskich uczelni zasadne wydaje się stworzenie osobnych związków zawodowych chroniących prawa doktorantów i młodych pracowników nauki, które dawałyby impuls i argumenty pozwalające na emancypację i opór. Warto wspomnieć, że obecnie istnieje już kilka organizacji, które walczą za pomocą presji symbolicznej (konsultacje społeczne, happeningi, pikiety, niewygodne pytania zadawane Ministerstwu 
Nauki i Szkolnictwa Wyższego, publikacje) o poprawę warunków pracy doktorantów i młodych pracowników (Obywatele Nauki, Komitet Kryzysowy Humanistyki Polskiej, Uniwersytet Zaangażowany, Nowe Otwarcie Uniwersytetu). Istnienie tych organizacji, a także stworzenie związków zawodowych potwierdzałoby kolejny element teorii ochrony godności autorstwa Hodsona, mówiący o konieczności stworzenia alternatywnego, niezależnego systemu znaczeń, który pozwoliłby na krytyczny dystans wobec patologii organizacyjnych i przeciwdziałanie im. Dwie pozostałe formy: budowanie demokratycznych relacji ze współpracownikami opartymi na relacji zaufania, szacunku i respektu, a także podejmowanie bezinteresownych, obywatelskich działań organizacyjnych, mających na celu ochronę dobra współpracowników, wydają się możliwe do urzeczywistnienia po osiągnięciu określonego poziomu emancypacji i świadomości konieczności stawiania oporu (Fleming i Spicer 2007; Bristow, Robinson i Ratle 2017).

Sposób, w jaki młodzi pracownicy nauki i doktoranci postrzegają i wykonują swoją pracę, rozumieją swoją unikalną odpowiedzialność i funkcje, interpretują swoją rolę, słowem, w jaki sposób przyjmują społeczną i profesjonalną tożsamość, zależy w dużym stopniu od doświadczanej kultury w uniwersytecie i jest kluczowe w kształtowaniu praktyk pracy, które wpływają na ekonomiczne, kulturowe, społeczne i polityczne rezultaty wyższej edukacji. Kształtowanie humanistycznej perspektywy w pracy akademickiej, opartej na wzajemnym zaufaniu, szacunku i sprawiedliwości, jest warunkiem koniecznym rozwoju uczelni wyższej, w tym kluczowym czynnikiem umożliwiającym postęp naukowy i tworzenie warunków sprzyjających ochronie i rozwoju godności w miejscu pracy. Wydaje się, że humanistyczna kultura akademicka wymaga próby rozwoju alternatywnych modeli oceny pracy bazujących na kryteriach jakościowych, z których najważniejsze to jakość dorobku naukowego, zdolność do refleksji i krytycznego rozumowania, umiejętność krytycznej dyskusji z autorytetami i tradycją oraz umiejętność działania na rzecz dobra wspólnego (Szadkowski 2015). Być może pozwoliłyby one znaleźć trzecią, humanistyczną drogę zarządzania uniwersytetem, wykraczającą poza imitację neoliberalnej mody i kulturę folwarczną.

\section{Literatura}

Alvesson, M. (2013). The Triumph of Emptiness: Consumption, Higher Education and Work Organization. Oxford: Oxford University Press.

Amaral, A., Meek, V.L., Larsen, I. M. (red.) (2003). The Higher Education Managerial Revolution? Dordrecht: Kluwer Academic Publishers.

Antonowicz, D. (2015). Między siłą globalnych procesów a lokalną tradycją. Polskie szkolnictwo wyższe $w$ dobie przemian. Toruń: Wyd. Nauk. UMK.

Arnaboldi, M., Lapsley, I., Steccolini, I. (2015). Performance management in the public sector: the ultimate challenge. Financial Accountability and Management. 31(1): 11-22. 
Barry, J., Chandler, J., Heather, C. (2001). Between the Ivory Tower and the Academic Assembly Line. Journal of Management Studies. 38(1): 88-101.

Batko, R. (2013) Golem, Awatar, Midas, Złoty cielec. Organizacja publiczna w ptynnej nowoczesności. Warszawa: Sedno.

Becher, T. Trowler, P. R. (2001). Academic Tribes and Territories: Intellectual Enquiry and the Culture of Disciplines. Buckingham: SRHE - Open University Press.

Beech, N. (2011). Liminality and the practices of identity reconstruction. Human Relations. 64(2): 285-302.

Bogt, H.J. ter, Scapens, R.W. (2012). Performance management in universities: Effects of the transition to more quantitative measurement systems. European Accounting Review. 21(3): 451-497.

Bolton, S.C. (2007) Dignity in and at Work. W: S. C. Bolton (red.). Dimensions of Dignity at Work (3-16). Oxford: Butterworth-Heinemann.

Bristow, A., Robinson, S., Ratle, O. (2017). Being an early-career CMS academic in the context of insecurity and 'excellence': the dialectics of resistance and compliance. Organization. http://journals.sagepub.com/doi/full/10.1177/0170840616685361 [dostęp 24.04.2017].

Broadbent, J., Laughlin, R. (2009). Performance management systems: A conceptual model. Management Accounting Research. 20(4): 283-295.

Brzeziński, J.M. (2015). „Trzej przyjaciele z boiska”. Jak cudownie powiększyć dorobek publikacyjny jednostki naukowej. Forum Akademickie. 7-8: 38-39.

Butler, N., Spoelstra, S. (2012). Your Excellency. Organization. 19(6): 891-903.

Craig, R., Amernic, J., Tourish, D. (2014). Perverse audit culture and accountability of the modern public university. Financial Accountability \& Management. 30(1): 1-24.

Crowley, M. (2012). Control and dignity in professional, manual and service-sector employment. Organization Studies. 33(10): 1383-1406.

Czarnecki, K. (2013). Nowe Zarządzanie Publiczne a reforma szkolnictwa wyższego w Polsce. Praktyka Teoretyczna. 1(7): 85-106. http://www.praktykateoretyczna.pl/PT_ nr7_2013_NOU/o8.Czarnecki.pdf [dostęp: 21.04.2017].

Czarniawska, B. (1997). Narrating the Organization. Dramas of Institutional Identity. Chicago - London: The University of Chicago Press.

Czarniawska, B. (2004) Narratives in Social Science Research. London: Sage.

Czarniawska, B. (2014). Social Science Research. From Field to Desk. Los Angeles: Sage.

Davies, W. (2014) The Limits of Neoliberalism. Authority, Sovereignty and the Logic of Competition. London: Sage.

Decramer, A., Smolders, C., Vanderstraeten, A. (2013). Employee performance management culture and system features in higher education: relationship with employee performance management satisfaction. The International Journal of Human Resource Management. 24(2): 352-371.

Diefenbach, T. (2009). New Public Management in public sector organizations: the dark sides of managerialistic “Enlightenment”. Public Administration. 87(4): 892-909.

Dierksmeier, C. (2016). Reframing Economic Ethics. The Philosophical Foundations of Humanistic Management. London: Palgrave. 
Dill, D. D. (1982) The management of academic culture. Notes on the management of meaning and social integration. Higher Education. 11: 303-320.

Düwell, M., Braarvig, J., Brownsword, R., Mieth, D. (red.) (2014). The Oxford Handbook of Human Dignity. Interdisciplinary Perspectives. Oxford: Oxford University Press.

Elliot, J. (2005). Using Narrative in Social Research. London: Sage.

Ergöl, H., Coşar, S. (2017) Universities in the Neoliberal Era. Academic Cultures and Critical Perspectives. London: Palgrave Macmillan.

Fleming, P., Spicer, A. (2007). Contesting the Corporation. Struggle, Power and Resistance in Organizations. Cambridge: Cambridge University Press.

Fontana, A., Frey, J.H. (2009) Wywiad. Od neutralności do politycznego zaangażowania. W: N.K. Denzin, Y.S. Lincoln (red.). Metody badań jakościowych (tom 2, 81-128). Warszawa: Wyd. Nauk. PWN.

Graeber, D. (2011). Debt. The First 5000 Years. Brooklyn - New York: Melvillehouse.

Gunn, A.M. (2011). The discursive construction of care when there is no care to be found: organizational life (re)framed by those on the socio-economic margins facing job loss. Culture \& Organization. 17(1): 65-85.

Hicks, D. (2016). A culture of indignity and failure of leadership. Humanistic Management Journal. 1(1): 113-126.

Hodson, R. (2001). Dignity at Work. Cambridge: Cambridge University Press.

Hryniewicz, J. (2012). Stosunki pracy $w$ polskich organizacjach. Warszawa: Scholar.

Jago, B.J. (2002). Chronicling an academic depression. Journal of Contemporary Ethnography. 31(6): 729-757.

Kallio, K.M., Kallio, T.J. (2014). Management-by-results and performance measurement in universities - implications for work motivation. Studies in Higher Education. 39(4): 574-589.

Kant, I. (1953). Uzasadnienie metafizyki moralności. Przeł. M. Wartenberg. Warszawa: PWN.

Karlsson, J.Ch. (2012). Organizational Misbehaviour in the Workplace. Narratives of Dignity and Resistance. Hampshire: Palgrave

Knights, D., Clarke, C.A. (2014). It's a bittersweet symphony, this life: Fragile academic selves and insecure identities at work. Organization Studies. 35(3): 335-357.

Kola, A.M. (2016). Doktoranci - grupa wybrana czy przegrana? Prezentacja wniosków studium teoretyczno-empirycznego na temat studiów doktoranckich w Polsce. Nauka i Szkolnictwo Wyższe. 2(48): 175-191.

Kostera, M. (2003). Antropologia organizacji. Metodologia badań terenowych. Warszawa: Wyd. Nauk. PWN.

Kostera, M., Pirson, M. (red.) (2017). Dignity and the Organization. London: Palgrave.

Kościelniak, C. (2015). Uniwersytet, rozwój, kultura. Poznań: Wyd. Nauk. UAM.

Kowzan, P., Zielińska, M., Kleina-Gwizdała, A., Prusinowska, M. (2016). „Nie zostaje mi czasu na prace naukowa”. Warunki pracy osób ze stopniem doktora, zatrudnionych na polskich uczelniach. Raport NOU. Gdańsk - Bydgoszcz - Warszawa: Nowe Otwarcie Uniwersytetu.

Kulczycki, E. (2017). Punktoza jako strategia w grze parametrycznej w Polsce. Nauka i Szkolnictwo Wyższe. 1(49): 63-78. doi: 10.14746/nisw.2017.1.4. 
Kwiek, M. (2016). Uniwersytet $w$ dobie przemian. Instytucje i kadra akademicka $w$ warunkach rosnacej konkurencji. Warszawa: Wyd. Nauk. PWN.

Kwiek, M., Antonowicz, D., Brdulak, J, Hulicka, M., Jędrzejewski, T., Kowalski, R., Kulczycki, E., Szadkowski, K., Szot, A., Wolszczak-Derlacz, J. (2016). Projekt założeń do ustawy Prawo o szkolnictwie wyższym. Poznań: Wyd. Nauk. WNS UAM.

Laudel, G., Gläser, J. (2008). From apprentice to colleague: The metamorphosis of early career researchers. Higher Education. 55(3): 387-406.

Leja, K. (2013). Zarządzanie uczelnią. Koncepcje i wspótczesne wyzwania. Warszawa: Wolters Kluwer Polska.

Lucas, K. (2015) Workplace dignity: communicating inherent, earned, and remediated dignity. Journal of Management Studies. 52(5): 621-646.

Lynch, K., Ivancheva, M. (2015). Academic freedom and the commercialisation of universities: A critical ethical analysis. Ethics in Science and Enviromental Politics. 15: 1-15.

Macfarlane, B. (2017) The ethics of multiple authorship: Power, performativity and gift economy. Studies in Higher Education. 42(7): 1194-1210.

Magala, S., Zawadzki, M. (2017). Performing Academics: Return to Meritocracy? W: C. Cannavale, F. Maimone, P. Malizia (red.). Evolution of the Post-Bureaucratic Organization (88-104). Hershey: IGI-Global Publisher.

Malsch, B., Tessier, S. (2015). Journal ranking effects on junior academics: Identity fragmentation and politicization. Critical Perspectives on Accounting. 26: 84-98.

McCloskey, D. (2010). Bourgeois Dignity: Why Economics Can't Explain the Modern World. Chicago: University of Chicago .

McKelvey, M., Holmén, M. (red.) (2009). Learning to Compete in European Universities. From Social Institution to Knowledge Business. Cheltenham - Northampton: Edward Elgar.

Morrissey, J. (2015) Regimes of performance: Practices of the normalised self in the neoliberal academia. British Journal of Sociology of Education. 36(4): 614-634.

Nierenberg, B., Batko, R., Sułkowski, Ł. (red.) (2015). Zarządzanie humanistyczne. Kraków: Wyd. Uniwersytetu Jagiellońskiego.

Otis, E.M. (2008). The dignity of working women: Service, sex, and the labor politics of localization in China's City of Eternal Spring. American Behavioral Scientist. 52(3): 356-376.

Otley, D. (1999). Performance management: a framework for management control systems research. Management Accounting Research. 10(4): 363-382.

Prasad, A. (2013). Playing the game and trying not to lose myself: a doctoral student's perspective on the institutional pressures for research output. Organization. 20(6): 936948.

Prawelska-Skrzypek, G. (2007). Przedmiot i metody badań w dziedzinie nauk humanistycznych w dyscyplinie nauk o zarządzaniu. Współczesne Zarządzanie. Kwartalnik środowisk naukowych i liderów biznesu. 1: 17-24.

Raineri, N. (2015). Business doctoral education as a liminal period of transition: Comparing theory and practice. Critical Perspective on Accounting. 26: 99-107.

Rosen, C. (2012). Dignity: Its History and Meaning. Cambridge, MA: Harvard University Press. 
Sarrico, C.S. (2010). On performance in higher education: Towards performance governance. Tertiary Education and Management. 16(2): 145-158.

Sayer, A. (2007) Dignity at work: Broadening the agenda. Organization. 14(4): 565-581.

Silver, H. (2003) Does a university have a culture? Studies in Higher Education. 28(2): 157-169.

Smeenk, S., Teelken, C., Eisinga, R., Doorewaard, H. (2009). Managerialism, organizational commitment, and quality of job performances among european university employees. Research in Higher Education. 50(6): 589-607.

Solska, E. (2008). Zmierzch kultury uniwersytetu? W: K. Leja (red.). Społeczna odpowiedzialność uczelni (73-88). Gdańsk: Katedra Zarządzania Wiedzą i Informacją, Wydział Zarządzania i Ekonomii, Politechnika Gdańska.

Sorokowski, P., Kulczycki, E., Sorokowska, A., Pisanski, K. (2017). Predatory journals recruit fake editor. Nature. 543: 481-483.

Strathern, M. (red.) (2000). Audit Cultures. Anthropological Studies in Accountability, Ethics and the Academy. London - New York: Routledge.

Stuesse, A.C. (2010) What's "justice and dignity" go to do with it? Migrant vulnerability, corporate complicity, and the state. Human Organization. 69(1): 19-30.

Styhre, A. (2014) Management and Neoliberalism: Connecting Policies and Practicies. New York - London: Routledge.

Sułkowski, Ł. (2016). Kultura akademicka: koniec utopii? Warszawa: Wyd. Nauk. PWN.

Szenajch, P., Małecka, M., Suwada, K. (2013). Nowe Otwarcie Uniwersytetu - wprowadzenie do tekstów rozproszonych. Praktyka Teoretyczna. 1(7): 63-72. http://www.praktykateoretyczna.pl/PT_nr7_2013_NOU/o6. Szenajch.pdf [dostęp: 24.04.2017].

Szadkowski, K. (2015). Uniwersytet jako dobro wspólne. Podstawy krytycznych badań nad szkolnictwem wyższym. Warszawa: Wyd. Nauk. PWN.

Szadkowski, K. (2016). Socially necessary impact/time: Notes on the acceleration of academic labor, metrics and the transnational association of capitals. Teorie Vědy/Theory of Science. 38(1): 53-85.

Szkudlarek, T. (2010). Inner University, Knowledge Workers, and Liminality. W: P. Thompson, M. Walker (red.). The Routledge Doctoral Student's Companion. Getting to Grips with Research in Education and Social Sciences (356-367). London: Routledge.

Szwabowski, O. (2014). Uniwersytet, fabryka, maszyna. Uniwersytet w perspektywie radykalnej. Warszawa: Książka i Prasa.

Tierney, W.G. (1988) Organizational culture in higher education: Defining the essentials. The Journal of Higher Education. 59(1): 2-21.

Tuchman, G. (2009). Wannabe U. Inside the Corporate University. Chicago - London: The University of Chicago Press.

Turner, V. (1966). The Ritual Process. Structure and Anti-Structure. Ithaca: Cornell University Press.

Williams, R. (2002). Performance Management. London: International Thomson Business Press.

Witkowski, L. (2011). Historie autorytetu wobec kultury i edukacji. Kraków: Impuls.

Wojtyła, K. (1969). Osoba i czyn. Kraków: Polskie Towarzysztwo Teologiczne. 
Ylijoki, O.-H. (2005). Academic nostalgia: a narrative approach to academic work. Human Relations. 58(5): 555-576.

Ylijoki, O.-H. (2010) Future orientations in episodic labour: Short-term academics as a case in point. Time \& Society. 19(3): 365-386.

Ylijoki, O.-H., Henriksson, L. (2017) Tribal, proletarian and entrepreneurial career stories: Junior academics as a case in point. Studies in Higher Education. 42(7): 1292-1308.

Zawadzki, M. (2014). Nurt krytyczny w zarzadzaniu: kultura, edukacja, teoria. Warszawa: Sedno.

Zawadzki, M. (2017). Last in the Food Chain. Polish Junior Academics and Doctoral Candidates in the Face of Performance Management. W: M. Izak, M. Kostera, M. Zawadzki (red.). The Future of University Education (63-84). London: Palgrave Macmillan.

Zielińska, M., Kowzan, P. (2016). Mobilność zagraniczna polskich doktorów - możliwości i bariery. Nauka i Szkolnictwo Wyższe. 1(47): 181-201. doi: 10.14746/nisw.2016.1.7.

\title{
Between the neo-liberalism and feudalism. The dignity of young academics in the context of transformation of the Polish university
}

\begin{abstract}
This paper presents the results of initial research about the dignity of people starting their career in a Polish university. Polish PhD students and junior academics are situated in a transitional stage between the feudalism and neo-liberalism as well as academial "independency" and "dependency," which might contribute to the politicization of their work identity. What is the impact of those ambivalent work conditions on their dignity? In the article I describe the neo-liberal changes in the Polish higher education, analyze the dignity in the workplace from the humanistic management perspective and present the results of qualitative pilot study.
\end{abstract}

KEYWORDS: academic culture, dignity, university, neoliberalism, performance management

CYTOWANIE: Zawadzki, M. (2017). Między neoliberalizmem a feudalizmem. Godność młodych naukowców w kontekście transformacji polskiego uniwersytetu, Nauka i Szkolnictwo Wyższe 1(49): 133-154. doi: 10.14746/nisw.2017.1.7. 